DOI: 10.14526/2070-4798-2020-15-1-82-88

\title{
The influence of "Isoton" system exercises on body content of female students of special medical groups
}

\author{
Lyudmila N. Kuznetsova, Aleksandra Yu. Anisimova, Ildus G. Gibadullin* \\ M.T. Kalashnikov State Technical University, Izhevsk, Russia \\ ORCID: oooo-Ooo2-7499-4533, a.mihailova@udm.ru \\ ORCID: oOoo-Ooo2-5899-91, lubarik17@rambler.ru \\ ORCID: oooo-ooo1-6386-1121,ffkis@istu.ru*
}

\begin{abstract}
The article is about the experimental methodology of using "Isoton" system of exercises. The aim of this methodology is to cause urgent training effects in the organism of those, who train. Planning the kind and the depth of urgent training effects is conditioned by that training effects. It should be achieved for the physical state and health in general improvement. Research methods. Scientific literature analysis and summarizing, experiment, methods of mathematical statistics. The experiment was held among female students of the $3^{\text {rd }}$ course of a special medical group, the control group trained according to adopted program. In the experimental group "Isoton" system exercises were used. Results. During the experiment we revealed the effectiveness of "Isoton" system exercises influence on body content of a person. It is proved that static-dynamic exercises influence on body content. In the experimental group the indices of body mass, fat-free mass, general water and general liquid increased, the level of active cell mass and the level of intracellular fluid also increased. There was also general weight and fat mass indices decrease. General metabolism stayed almost unchanged.

Keywords: method of bioimpedancometric study, students, "Isoton" system exercises, body
\end{abstract} content.

For citation: Lyudmila N. Kuznetsova, Aleksandra Yu. Anisimova, Ildus G. Gibadullin*. The influence of "Isoton" system of exercises on body content of female students of special medical groups. Russian Journal of Physical Education and Sport. 2020; 15(1): 69-73. DOI: 10.14526/2070-4798-2020-15-1-82-88

\section{INTRODUCTION}

The urgency of this work is conditioned by the fact that students of technical higher educational establishments don't get necessary physical load. It leads to many diseases development, immunity and mental activity decrease.

One of the most developed units of morphology is body content studying. Nowadays body content studying is defined into a separate branch of the science. New research methods, software program, the works of scientists are introduced into this science. Bioimpedance analysis nowadays is one of the most popular research methods of studying body content of a person.

In order to study body content we used the whole available diagnostic range of medical methods, for example plethysmography, the method of infrared reflection, ultrasonic investigation, X-ray and others. However, the most effective method of body content study in the patients is considered bioimpedance analysis. The instruments for its organization are simple and the results are easy for interpretation [2].

Bioimpedance diagnostics on the basis of water, protein and fat metabolism indices helps to estimate the risk level of many diseases and serious deviations development in the work of an organism. These diseases include hypertensive disease and its consequences, gallstone and kidney stone disease and also locomotor apparatus diseases development. With the help of bioimpedance analysis it is possible to reveal serious chronic diseases development, such as cancer, AIDS, cirrhosis) [1].

"Isoton" is a system of exercises from health improving physical culture.

Training according to "Isoton" system has the aim to improve health state, working capacity, physical health, appearance (body shape, body content), social, life and labor activity in men and women of a wide age range.

The system was named "Isoton" according 
to the type of physical exercises, which take the central place - isotonic exercises, when the muscles experience constant tension during the attempt; and according to the main effect, which is achieved as a result of its use, high "life tonus" of a person, who trains according to "Isoton" system exercises.

During the main principles of "Isoton" creation and substantiation we used an imitating modeling with the help of computer graphics of physiological systems and biochemical processes in an organism and a wide spectrum of physical influence on a person analysis. Then the most effective means and methods of physical health improvement were created, selected and combined into one system by means of organism functional abilities important systems increase (endocrine, immune, digestive, cardiovascular, muscular and etc.) taking into account the effect of the lessons in terms of negative psychic states correction (depressive and etc.) [4].

In case of power exercises correct technique the speed of muscles contraction is not high, the degree of tension - 30-60\% from maximum arbitrary force, amplitude is the average and full, in the cycle of movement there can be pauses or the elements of static retension. Muscles usually don't relax till the end of the attempt.

The main distinctive feature of this kind of muscles work is local blood circulation violation. It is together with considerably high degree of muscles tension quickly (during 15-30 seconds) creates hypoxic conditions inside the muscle fibers. It increases anaerobic glycolysis not only in quick muscle fibers, in which its speed is always high, but in slow ones, oxidative. As a result in all types of muscle fibers the concentration of creatine phosphate decreases, hydrogen ions, lactate, free creatine accumulate, other physiological and biochemical phenomena happen. They are typical for a traditional training with big loads.

The aim of any training lesson is to cause rational urgent training effects in an organism. At the same time, planning the kind and depth of urgent training effects is determined by those delayed training effects. It is demanded to achieve physical state and health improvement [3].

The duration of the attempt for each muscle group leads to considerable muscles tiredness and to sufficiently intensive pain in tired muscles. A person tries to overcome it owing to psychic tension. In this situation the activation of sympathoadrenal and other parts of hormone system, together with metabolites accumulation create so called anabolic effect. They provide cells genetic apparatus activation and intensify the synthesis of the definite proteins [5-9].

In order to activate the processes, which lead to capillaries density (as the preconditions for aerobic abilities, arterial pressure normalization and others), the training process should include several attempts for one and the same muscle group. In this case alternation of a continuous hypoxic state of active muscles during the attempt and maximum blood circulation through muscle tissue after its end activates angiogenesis. It is capillary network increase.

Hypertrophy of the contracting elements of muscles, capillary network increase and anabolic atmosphere creation in an organism after the end of the training process is the main aim and effect of isotonic training. The last factor is an anabolic hormone background. It can preserve during 1-2 days after the training, is its most important effect, as it leads to an intensified synthesis of tissue-specific proteins not only in muscles, but also in all tissues. They have receptors to these hormones, in particular cardiovascular, hormonal, immune, digestive, systems and other important organs. Above we supposed that this mechanism is one of the main mechanisms. It causes health improving effect of isotonic, static-dynamic and other physical exercises [6-12]. Moreover, during static-dynamic training: there is psychic tension (at the end of the attempt) and relaxation alternation during the pauses of rest; a long time period there is a high level of partial tension of carbon dioxide in blood as a result of anaerobic reactions activation; the combination of the increased carbon dioxide concentration in blood. They stimulate respiratory center and a deep "diaphragmatic" breathing through the nose increases the amplitude (during inhalation and exhalation) of a partial oxygen tension in blood. These urgent effects provide psychic processes (psychic relaxation effect) and 
vascular reactions normalization.

\section{MATERIALS AND METHODS}

In order to study body content we used bioimpedancemetric study method. It was held on the basis of Izhevsk State Technical University, on "Aist" analyzer according to standard four-electrode scheme. This method helped to estimate the changes of the following indices: the volume of water in an organism (VWO), cellular liquid (CL), extracellular liquid (ECL), fat body mass (FBM), lean body mass (LBM), active cellular mass (ACM), skeletomuscular mass (SMM), body mass index (BMI), relative metabolism, main metabolism.

Before the beginning of the research the following parameters were written: age, gender, height, weight, the size of the wrist. The information was written for bioimpedanc analysis program. The respondent had to be isolated from outer currentconducting objects.

As the respondents we chose the female students of the $3^{\text {rd }}$ course. They belong to special medical group. During physical culture lessons students fulfilled the exercises from "Isoton" system. The exercises were presented in a form of smooth squattings (not complete squat), shoulder dip from knees (the amplitude of movements is not complete), in prone position, legs apart, body lifting. At the first (introductory) lesson each attempt of the exercise fulfillment took 30 seconds. At other lessons the time of the exercise fulfillment was 1 minute 15 seconds. The number of attempts stayed the same. The rest part of the lesson respondents trained according to the adopted program. The control group trained according to the adopted program, without using "Isoton" system of exercises.

\section{Results and Discussion}

In order to study body content with the help of bioimpedance method during physical culture lessons in the experimental group students used the exercises of "Isoton" system. The exercises were presented in a form of smooth squattings (not complete squat), shoulder dip from knees (the amplitude of movements is not complete), in prone position, legs apart, body lifting. At the first (introductory) lesson each attempt of the exercise fulfillment took 30 seconds. At other lessons time of the exercise fulfillment was 1 minute 15 seconds, the number of attempts stayed the same. The rest part of the lesson respondents trained according to the adopted program. The control group trained according to the adopted program, without using "Isoton" system of exercises.

Before the beginning and after the experiment we held bioimpedance study in order to study body content of the respondents.

Table 1 - Comparative indices of body content among students of the experimental and control groups before and after the experiment

\begin{tabular}{|c|c|c|c|c|c|c|c|}
\hline \multirow{2}{*}{ No } & \multirow{2}{*}{ TESTS } & \multicolumn{2}{|c|}{$\begin{array}{c}\text { Before the } \\
\text { experiment }\end{array}$} & After the experiment & \multicolumn{2}{c|}{ Increase /Decrease } \\
nof & EG & CG & EG & CG & EG & CG \\
\hline 1 & Body mass index & 20,3 & 20,7 & 19,7 & 19,7 & 3 & 1 \\
\hline 2 & Weight & 53,5 & 54 & 51,8 & 54,1 & 3 & 0,2 \\
\hline 3 & Ft mass (kg) & 13,1 & 13,3 & 12,1 & 13,3 & 7,5 & 0,5 \\
\hline 4 & Fat mass (\%) & 24,4 & 22,7 & 23,4 & 22,8 & 4 & 0,2 \\
\hline 5 & Lean body mass (kg) & 40,4 & 42,1 & 41,4 & 42,1 & 2,5 & 0,5 \\
\hline 6 & Active cellular mass (kg) & 25,4 & 24,9 & 26,9 & 24,8 & 6 & 0,2 \\
\hline 7 & Active cellular mass (\%) & 47,4 & 45,2 & 49,1 & 45,1 & 3,5 & 0,1 \\
\hline
\end{tabular}




\begin{tabular}{|c|c|c|c|c|c|c|c|}
\hline 8 & General water (l) & 29,5 & 30,8 & 28,8 & 30,7 & 2 & 0,2 \\
\hline 9 & General liquid (l) & 26,7 & 28,1 & 26,1 & 28,2 & 2 & 0,2 \\
\hline 10 & Extracellular liquid (1) & 9,6 & 11,1 & 9,5 & 10,9 & 1 & 1 \\
\hline 11 & Intracellular liquid (l) & 17,06 & 17,1 & 16,6 & 17,1 & 3 & 0 \\
\hline 12 & $\begin{array}{c}\text { General metabolism } \\
\text { (kcal) }\end{array}$ & 1370,1 & 1381 & 1367 & 1380 & 0,2 & 0,2 \\
\hline
\end{tabular}

The value of the received Student t-test is more than critical one (the level of validity $\mathrm{p}<0,05$ ). So the revealed differences are statistically valid.

As we see from the results, at the initial stage of the research both groups had almost the same parameters of body content. After the end of the training lessons according to "Isoton" system exercises the indices of some parameters of students from the experimental group changed. Body mass index increased in the experimental group for $3 \%$, in the control group the results stayed unchanged. We also saw general weight decrease in the female students from the experimental group for $3 \%$, fat mass decrease was for $7,5 \%$, but there was lean body mass increase for $2,5 \%$. The level of active cellular mass increased in the experimental group for $6 \%$, and the percentage of active cellular mass increased for 3,5\%. General water and general liquid increased in an organism of the respondents for $2 \%$, the level of extracellular liquid increased for $3 \%$. The main metabolism stayed almost the same, it increased for $0,2 \%$.

There were almost no changes in the indices of the control group. This situation is caused by the fact that the students from this group trained according to physical culture program. It was created for the special medical group. It should be noted that the exercises of "Isoton" system are not contraindicated for the students from the special medical group. The changes in body in the experimental group are first of all connected with the peculiarities of isotonic exercises.

The diagram shows the difference between the results of the experimental and control groups.

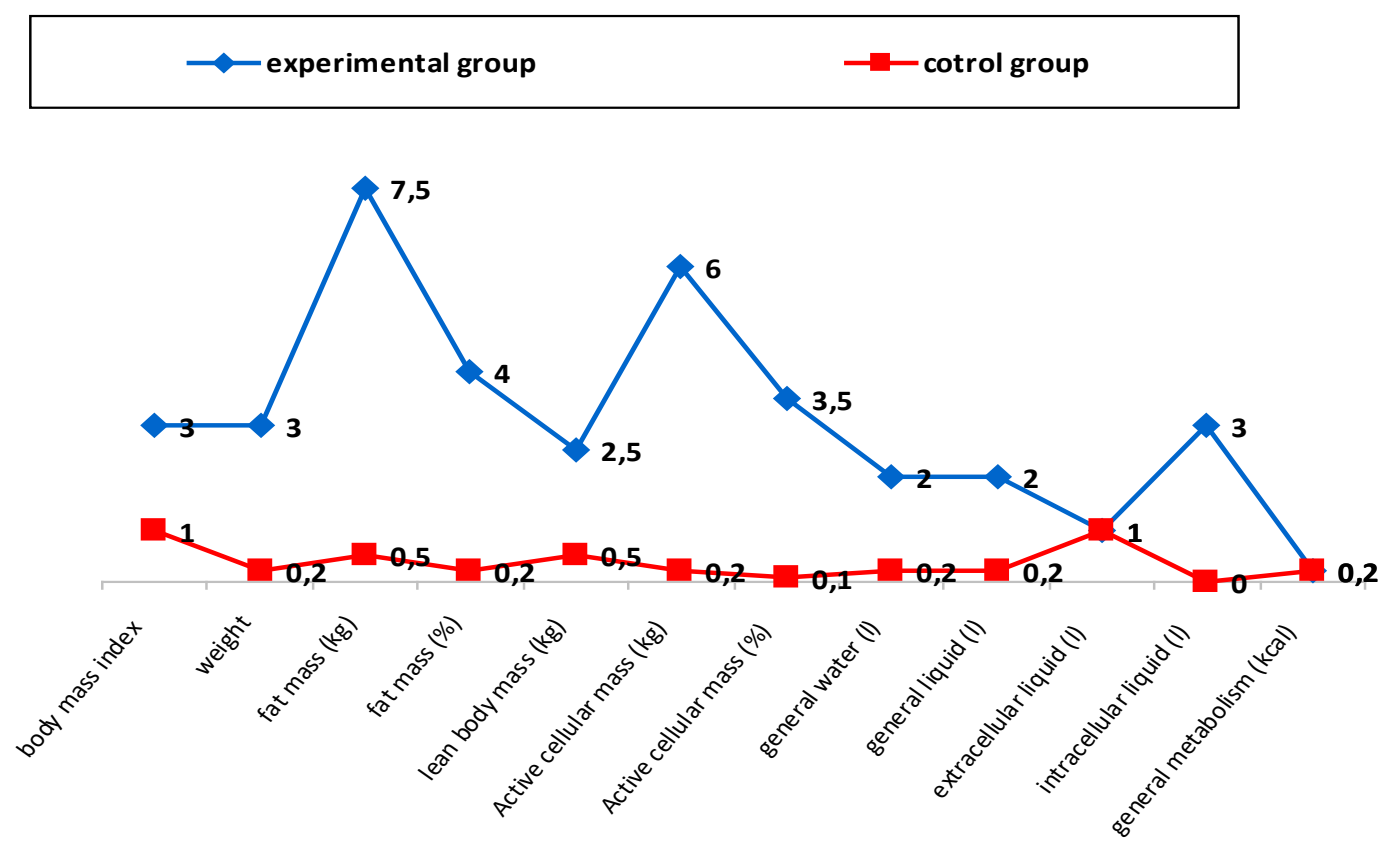

Picture 1 - Comparative diagram of the experimental and control groups 


\section{CONCLUSION}

During the experiment we revealed the effectiveness of "Isoton" system of exercises influence on body content of a person. It is proved that static-dynamic exercises influence on body content. BMI increased in the experimental group for $3 \%$, in the control group the result didn't change. There was also general weight (3\%) and fat mass $(7,5 \%)$ indices, percentage part of fat mass in an organism (4\%) decrease in the experimental group. LBM increased (2,5\%). The level of active cellular mass increased in the experimental group for $6 \%$, and percentage of ACM increased for 3,5\%. General water and general liquid increased in an organism for $2 \%$, the level of extracellular liquid increased for $3 \%$. The main metabolism stayed almost unchanged (increased for $0,2 \%$ ).

\section{REFERENCES}

1. Efimova T.G., Bulavina T.A. Physical culture at higher educational establishments. Materialy Mezhdunarodnojnauchno-prakticheskoj konferencii [Materials of the International scientificpractical conference]. Minsk. 1995; 2: 77-78.

2. Burukhin S. F. Gymnastics is very important. Fizicheskaya kul'tura $v$ shkloe. 2000: 10-12 [In Russ.].

3. Ermolaev Yu. A. [Age-related physiology: Manual for students of pedagogical higher educational establishments]. Moscow: High school. 1985: 7-9 [In Russ.].

4. Aukhadaev E.I., Galeev S.S., Safin M.R. [Physical training lessons at special and preparatory medical groups: methodical manual]. Moscow: High school. 1986: 19-22 [In Russ.].

5. Nikolaev D.B., Smirnov A.V., Bobrinskaya I.G., Rudnev S.G. [Bioimpedance analysis of body content]. Moscow: Nauka. 2009:
392 .

6. Ivanov G.G., Baluev E.B., Petukhov A.B. Bioimpedance method of body content determination. Vestnik RUNF. 2000; 3: 66-73 [In Russ.].

7. Andersen L.B., Wedderkopp N., Hansen H.S., Cooper A.R., Froberg K. Biological cardiovascular risk factors cluster in Danish children and adolescents: The European Youth Heart Study. Preventive Medicine. 2003; 37: 363-376.

8. Eisenmann J.C., Welk G., Wickel E.E., Blair S.N. Combined influence of cardiorespiratory fitness and body mass index on cardiovascular disease risk factors among 8-18 year old youth: The Aerobics Center Longitudinal Study. International journal of Pediatric Obesity. 2007b; 2: 66-72.

9. Mesa J.L., Ruiz J.R., Ortega F.B., Warnberg J., Gonzalez-Lamuno D., Moreno L.A., et al. Aerobic physical fitness in relation to blood lipids and fasting glycaemia in adolescents: Influence of weight status. Nutrition, Metabolism and Cardiovascular Diseases. 2006; 16: 285-293.

10. Mota J., Guerra S., Leandro C., Ribeiro J., Duarte J. Association of maturation, sex, and body fat in cardiorespiratory fitness. American journal of Human Biology. 2002; 14: 707-712.

11. Gibadullin I.G., Korbit M.I., Voropai M.K., Smirnova I., Smirnova K. Dynamics of respiratory system indices among biathlonists during a long-term training. Pedagogikopsihologicheskie I medico-biologicheskie problemy fizicheskoj kul'tury I sporta = The Russian Journal of Physical Education and Sport. 2018; 13(2): 3237. DOI 10.14526/02_2018_305[In Russ., In Engl.]

12. I.G. Gibadullin, K.M. Kasumov. The training process planning of 9-11 year-old skierssprinters. Pedagogiko-psihologicheskie I medicobiologicheskie problemy fizicheskoj kul'tury I sporta = Pedagogico-psychological and medicobiological problems of physical culture and sport. 2015; 10(1): 32-36. URL: http://journalsport.ru/ index.php/ru/arkhiv-nomerov?id=382 [In Russ., In Engl.].

\section{Submitted: 20.02.2020}

\section{Author's information:}

Lyudmila N. Kuznetsova - Candidate of Pedagogics, Associate Professor, M.T. Kalashnikov State Technical University, 426069, Russia, Izhevsk, Studencheskaya str., House 7.

Aleksandra Yu. Anisimova - Candidate of Pedagogics, Associate Professor, M.T. Kalashnikov State Technical University, 426069, Russia, Izhevsk, Studencheskaya str., House 7.

Ildus G. Gibadullin - Doctor of Pedagogics, Professor, M.T. Kalashnikov State Technical University, 426069, Russia, Izhevsk, Studencheskaya str., House 7, e-mail: ffkis@istu.ru 